\title{
A CONTROL LIST FOR THE SYSTEMATIC IDENTIFICATION OF DISTURBANCE FACTORS
}

\author{
Welzbacher, Peter; \\ Vorwerk-Handing, Gunnar; \\ Kirchner, Eckhard
}

Technical University of Darmstadt; Institute for Product Development and Machine Elements (pmd)

\begin{abstract}
The importance of considering disturbance factors in the product development process is often emphasized as one of the key factors to a functional and secure product. However, there is only a small number of tools to support the developer in the identification of disturbance factors and none of them yet ensures that the majority of occurring disturbance factors is considered. Thus, it is the aim of this contribution to provide a tool in form of a control list for the systematic identification of disturbance factors. At the beginning of this contribution, the terms "disturbance factor" and "uncertainty" are defined based on a literature review and different approaches for the classification of uncertainty are presented. Subsequently, the fundamentals of multipole based model theory are outlined. Moreover, a first approach in terms of a control list for a systematic identification of disturbance factors is discussed. Based on the discussed approach and taking the identified weaknesses as a starting point, a control list is presented that combines the existing basic concept of the control list with the fundamentals of multipole based model theory.
\end{abstract}

Keywords: Design methods, Uncertainty, Early design phases, Disturbance factor

\section{Contact:}

Welzbacher, Peter

Technical University Darmstadt

Institute for Product Development and Machine Elements (pmd)

Germany

peter.welzbacher@tu-darmstadt.de

Cite this article: Welzbacher, P., Vorwerk-Handing, G., Kirchner, E. (2021) 'A Control List for the Systematic Identification of Disturbance Factors', in Proceedings of the International Conference on Engineering Design (ICED21), Gothenburg, Sweden, 16-20 August 2021. DOI:10.1017/pds.2021.6 


\section{INTRODUCTION AND MOTIVATION}

Considering disturbance factors in the framework of the product development process is often emphasized as key to a functional, secure and stable product. For example, Pahl et al. (2007) state that "disturbance factors such as temperature, humidity, dust, vibrations etc. can cause effects that should not be neglected" (Pahl et al., 2007, p. 521). Thus, it is crucial for the success of the later product to identify and consider these disturbance factors as well as their effects on the functionality of the product with regard to robust design as early as possible in the product development process respectively already in the early phase of concept development (cf. Pahl et al., 2007; Taguchi et al., 2005)

For the identification and evaluation of possible negative effects of disturbance factors in terms of failures, a variety of standardised methods can be used, for example, the failure tree analysis (FTA), failure mode and effects analysis (FMEA) or hazard and operability analysis (HAZOP). Moreover, effect catalogues, for example, the one proposed by Koller (1998) can be used to systematically identify possible physical effects that are caused by disturbance factors and may influence the functionality of the product negatively (cf. Vorwerk-Handing et al., 2020). However, all these methods and approaches have in common that they do not include or refer to a systematic approach or tool to support the developer in the systematic identification of occurring disturbance factors.

Thus, it cannot be ensured that the majority of occurring disturbance factors that may result in functioncritical effects is identified. This results in a remaining uncertainty regarding the functionality of the product to be developed under real conditions of use. This problem is also often addressed in the context of uncertainty management, for example, in the Variation Mode and Effects Analysis by Chakhunashvili et al. (2004). Oftentimes, it is simply assumed that the developer has already enough knowledge and/or experience to be able to identify all relevant disturbance factors (cf. Pahl et al., 2007).

Especially in terms of industry 4.0 the identification and consideration of disturbance factors is of great importance to ensure the functionality of measuring functions to be integrated into technical systems as a first step towards cyber-physical systems (cf. Vorwerk-Handing et al., 2018). Due to the above-mentioned lack of support of the developer in the identification of disturbance factors, there is always uncertainty remaining regarding the functionality and robustness of these functions.

The aim of this contribution is therefore to provide a suitable tool in the form of a control list to support the developer as early as possible in the identification of occurring disturbance factors and consequently create a basis for the subsequent systematic identification and consideration of the caused effects.

\section{FUNDAMENTALS AND STATE OF RESEARCH}

This section begins with defining the terms "disturbance factor" and "uncertainty" based on a literature review to ensure a uniform understanding of these terms for the following part of this contribution. Furthermore, different existing approaches for the classification of uncertainty are portrayed. Subsequently, as basis for the later on presented control list, the fundamentals of multipole based model theory are described and a first approach in terms of a control list for the systematic identification of disturbance factors is presented and discussed.

\subsection{Definition of disturbance factor}

In control engineering, a disturbance factor, also referred to as disturbance variable, is described as an unwanted, independent and often unpredictable input quantity of a technical system that arises from the systems surrounding (cf. Heinrich and Schneider, 2019). The overall goal in control engineering is to eliminate or at least minimise the impact of these factors on the system in order to be able to fulfil an intended function without the occurrence of errors and/or failures and ensure the systems stability (cf. Feldhusen and Grote, 2013).

In robust design the overall goal is to design a system that is insensitive, i.e. robust, and thus will be least affected by "noise factors" (cf. Taguchi et al., 2005; Andersson, 1997). In this context, Taguchi et al. (2005) define "noise factor" as any uncontrollable factor that causes a variation in product quality. Furthermore, three basic types of noise are distinct:

- noise due to external causes (for example temperature or vibration),

- noise due to internal causes (for example wear or material conversion) and

- noise due to part-to-part or product-to-product variation (for example production imprecisions). 
According to Taguchi et al. (2005), disturbance factors, as described in the context of control engineering, are a subtype of noise factors and are referred to, in the context of robust design, as noise due to external causes.

Both described views have in common, that a disturbance factor or noise due to external causes is seen as an unwanted input originating from the surrounding and influences the behaviour of the system in a negative way. This common understanding of a disturbance factor is used in the following.

\subsection{Definition of uncertainty}

Uncertainty is a term that is used in many scientific disciplines with different understandings (cf. Hanselka and Platz, 2010). Thus, it is not possible to define this term in a way to fit all the different understandings. As a consequence, the following definition and explanation of the term "uncertainty" is referring exclusively to the understanding of uncertainty in product development.

Galbraith (1973) describes uncertainty in terms of a task as "the difference between the amount of information required to perform the task and the amount of information already possessed" (Galbraith, 1973, p. 5). This understanding of uncertainty as a lack of information is taken up in a more general way in the ISO Guide 73 (2009) in which uncertainty is defined as "state, even partial, of deficiency of information related to, understanding or knowledge of, an event, its consequence, or likelihood" (International Organization for Standardization, 2009, p. 2). In the further course of this contribution, the definition from the ISO Guide 73 (2009) is used.

\subsection{Approaches for classification of uncertainty}

In literature, uncertainty is often distinct based on:

- its manifestation,

- its level and/or

- its nature.

The categorisation of uncertainty according to its manifestation refers to the location in a system model where uncertainty occurs. A distinction is made between "context uncertainty", "model uncertainty", "data uncertainty" and "phenomenological uncertainty" (cf. Kreye et al., 2011). The different manifestations of uncertainty are shown in Figure 1 in a system model.

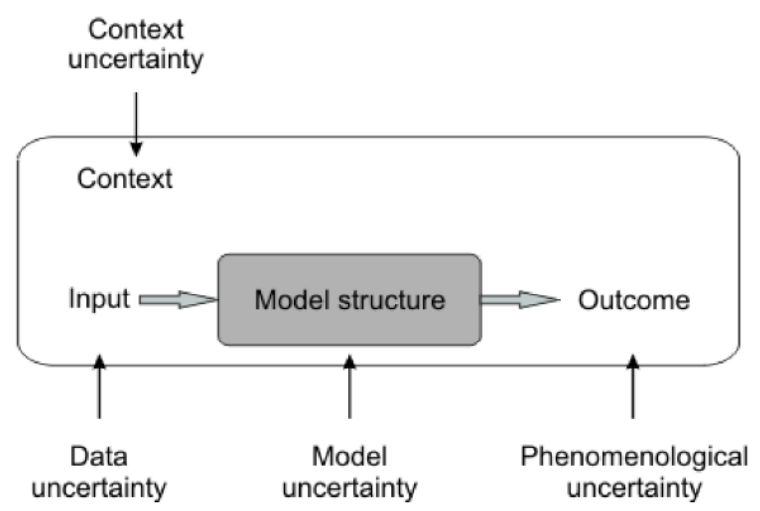

Figure 1: Manifestation of uncertainty in a system model (Kreye et al., 2011)

The context of a system describes the circumstances and conditions that surround the technical system under consideration. Hence, context uncertainty describes the potential deficiency from influence of the context on the considered system. Data uncertainty, also referred to as input uncertainty, is the uncertainty that is connected to the input of a system or its model. However, input does not only include the actual input of the system or its model but also its design parameters. Uncertainty that results from modelling inaccuracies, made consciously or unconsciously, for example, in terms of simplified relations used in the system model, are designated as model uncertainty. Model uncertainty may result in a discrepancy between the predicted and the real system behaviour. The last type of manifestation of uncertainty is phenomenological uncertainty. Phenomenological uncertainty refers to the unpredictability of the future that is caused by unknown events or influences. It is, per definition, impossible to fully know or model this manifestation because there may always be the influence of an unexpected, and thus neglected, event. (cf. Walker et al., 2003; Kreye et al., 2011) 
The level of uncertainty refers to the amount of available and/or reliable information about an uncertainty affected quantity, for example, a design parameter. According to Walker et al. (2003), the spectrum ranges from "total ignorance" up to "determinism". This idea for a classification of uncertainty was taken up by the Collaborative Research Centre (CRC) 805, refined in terms of the definition of the individual levels and extended regarding the knowledge about the effect of uncertainty. The uncertainty model of the CRC 805 is shown in Figure 2. At this point it must be noted that determinacy is an unattainable ideal in reality. (cf. Walker et al., 2003; Lotz, 2018; based on Engelhardt et al., 2010)

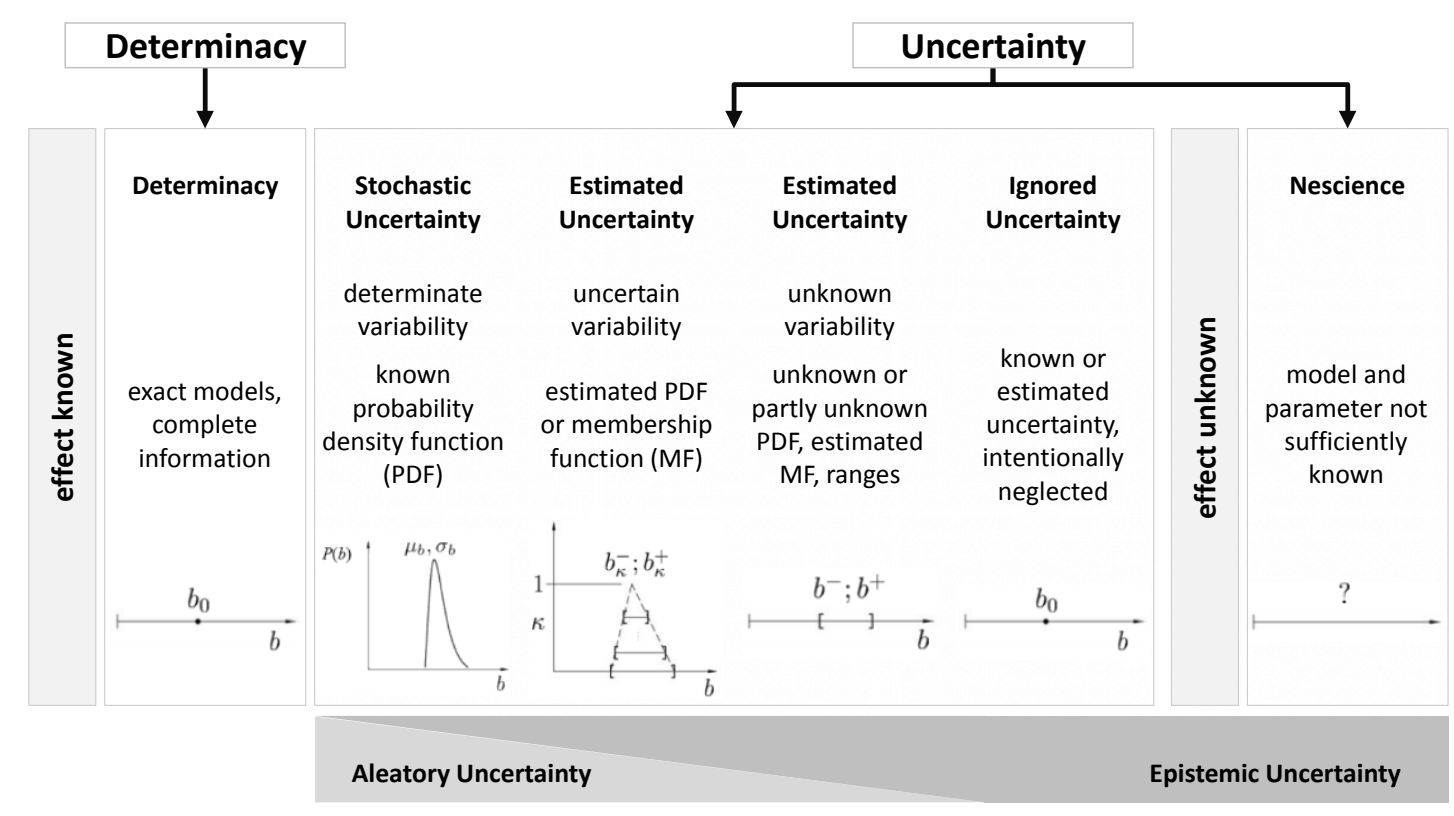

Figure 2: Uncertainty model of the CRC 805 (following Lotz, 2018)

In contrast to that, the nature of uncertainty describes the kind of relationship between uncertainty and information. Two types of uncertainty are distinct: epistemic and aleatory uncertainty. Epistemic uncertainty is uncertainty that results from a lack of information and thus can be reduced by gaining more information (cf. Oberkampf et al., 2002; Walker et al., 2003). Due to that, epistemic uncertainty is also often referred to as reducible uncertainty. In contrast to that, aleatory uncertainty cannot be reduced by gaining more information. It is present under the assumption that the system is fully describable and complete information exists, which is why it is also called irreducible uncertainty. It is caused by inherent variation associated with the system under consideration or its environment (cf. Oberkampf et al., 2002; Walker et al., 2003). The classification of uncertainty according to its nature is also shown in Figure 2 as bar in the lower part. It has to be noted that the bar represents the relative share of the individual type of uncertainty and not the absolute.

\subsection{Fundamentals of multipole based model theory}

The multipole-based model theory is used to create abstract cross-domain models of technical systems based on elementary principles of conservation of energy using concentrated network elements with two or more defined pols. The poles act as connectors between the different locally and functionally delimited network elements from different physical domains and allow them an energy transfer. Examples of physical domains are mechanics, electricity, hydraulics or thermodynamics. (cf. Janschek, 2010)

The basic idea of multipole-based model theory is that the energy transfer between different network elements is characterised by two generalised energy variables: a generalised flow variable $f$ and a generalised effort variable $e$ (cf. Wellstead, 1979). A generalised flow variable $f$ describes a variable that travels through a network element and can be measured at a single pole of the element, for example an electric current $I$. In contrast to that, a generalised effort variable $e$ can only be measured between two poles of a network element, for example an electric voltage $U$. (cf. Janschek, 2010)

The difference between these two variables is illustrated in Figure 3 using a concentrated network element with two poles. 


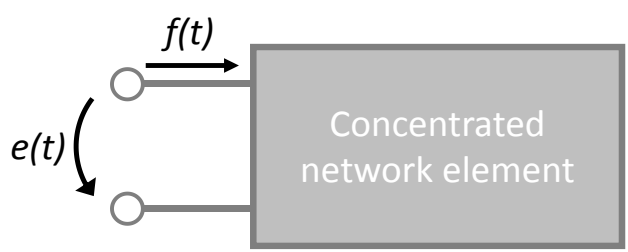

Figure 3: Concentrated network element with two poles (cf. Janschek, 2010)

The resulting generalised energy $E(t)$ that is transferred between two different network elements over the period of time $t$ is calculated using equation (1) (cf. Janschek, 2010).

$$
E(t)=\int_{t_{0}}^{t} P(\tau) d \tau=\int_{t_{0}}^{t} f(\tau) \cdot e(\tau) d \tau
$$

Due to the circumstance that there is only a limited number of existing physical domains, there is also only a limited number of generalised energy variables to describe the energy transfer between different network elements.

\subsection{Previous work}

Based on the list of standardised disturbance factors by Mathias (2016), Vorwerk-Handing et al. (2020) developed a control list to support the developer in the systematic identification of disturbance factors in the early phase of the product development process. For this purpose, the different standardised disturbance factors defined by Mathias (2016) were first assigned to their corresponding physical domains. Subsequently, each standardised disturbance factor, called potential disturbance variable by Vorwerk-Handing et al. (2020), was linked with its corresponding so-called physical influencing variables that directly act on, and thus influence, the considered technical system (cf. Vorwerk-Handing et al., 2020). An extract of the control list by Vorwerk-Handing et al. (2020) is shown in Figure 4.

\begin{tabular}{|c|c|c|c|}
\hline $\begin{array}{c}\text { Potential } \\
\text { disturbance } \\
\text { variable }\end{array}$ & $\begin{array}{l}\text { Picto- } \\
\text { gram }\end{array}$ & $\begin{array}{l}\text { Influencing } \\
\text { variable(s) }\end{array}$ & $\begin{array}{l}\text { Occurrence } \\
\text { \& Quanti- } \\
\text { fication }\end{array}$ \\
\hline $\begin{array}{l}\text { Homo- } \\
\text { geneous } \\
\text { el. field }\end{array}$ & 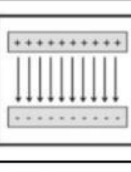 & $\begin{array}{l}\text { Force F } \\
\text { El. field } \mathrm{E}_{\mathrm{el}} \\
\text { El. charge q } \\
\text { El. capacity C }\end{array}$ & $\square$ \\
\hline $\begin{array}{l}\text { Electromag. } \\
\text { field (static) }\end{array}$ & & $\begin{array}{l}\text { Force F } \\
\text { Mag. flux } \\
\text { density B }\end{array}$ & $\square$ \\
\hline$\ldots$ & $\ldots$ & $\ldots$ & $\ldots$ \\
\hline
\end{tabular}

Figure 4: Extract of the disturbance factor control list (Vorwerk-Handing et al., 2020)

The influencing variables of the occurring potential disturbance variables can be used in a subsequent step for a systematic identification of potential effects of these disturbance variables on a technical system to be developed. Therefore, the different influencing variables are considered as inputs of "unintended" physical effects that may affect the systems functionality or stability in a negative way. These physical effects are called unintended because they are not intended in terms of the basic physical concept of the technical system to be developed. For the systematic identification of unintended physical effects, physical effect catalogues can be used, for example the one proposed by Koller (1998) or Vorwerk-Handing (2021). A detailed description of the identification process of unintended physical effects can be found in Vorwerk-Handing et al. (2020) and will not be further elaborated here as it is not in the focus of this publication. (cf. Vorwerk-Handing et al., 2020)

However, the control list by Vorwerk-Handing et al. (2020) has two major weaknesses. On the one hand, the control list builds up on the list of standardised disturbance factors by Mathias (2016). The major problem of this list is that the methodology that was used to identify and define these standardised disturbance factors is unclear. This results in ambiguities, for example, why there is a distinction made between heat supply and heat dissipation, although both describe a heat transfer in general, and which benefits result from this distinction. In addition to that, it stays unclear why the 
different mechanisms of heat transfer - conduction, convection or radiation - are not included in the list. Another example for those ambiguities is that infra- and ultrasound (as sound that is inaudible to humans) are included in the list of standardised disturbance factors, but audible sound in general is not. This example also illustrates that the level of detail in the list of standardised disturbance factors is not uniform. On the other hand, in terms of the influencing variables, Vorwerk-Handing et al. (2020) do not clearly differentiate between actual physical variables that result from the standardised disturbance factors and the ones resulting from subsequent unintended physical effects. An example for this unclear differentiation is shown in Figure 4 for the disturbance factor "Homogeneous electric field", where the force $F$ is listed as a physical influencing variable. The force $F$ acting in a homogeneous electric field is caused by Coulomb's law and thus is the consequence of an unintended physical effect, it is therefore not a physical influencing variable.

Regardless of the problems described above, the basic idea of the control list by Vorwerk-Handing et al. (2020) has a high potential to support the developer in the early systematic identification of disturbance factors and to provide a basis for the subsequent identification of caused unintended effects by means of physical effect catalogues. In order to benefit from the full potential of this basic idea, it is necessary to solve the problems described above.

\section{CONTROL LIST FOR THE SYSTEMATIC IDENTIFICATION OF DISTURBANCE FACTORS}

Although disturbance factors, as defined in section 2.1, originate only from the surrounding of the technical system, it must be considered that the technical system itself may influence and thus change its own environment, for example, in the form of secondary variables caused during the fulfilment of the primary function of the technical system. An example of such a secondary variable is the thermal power dissipation of a running electric drive that is emitted into the environment. Consequently, when identifying disturbance factors, it is necessary to consider not only the given environment of a technical system but also the secondary variables originating from the technical system itself that may influence and thus change the environment. As described in section 2.3, according to Kreye et al. (2011), disturbance factors result in context uncertainty. By identifying and quantifying potentially occurring disturbance factors, the resulting context uncertainty is determined. This information about the different occurring disturbance factors can then be used in a later step as reference for the development of suitable and effective robust design measures to increase the robustness of the system against these disturbance factors if needed. Basic approaches for the development of robust design measures are described by Mathias et al. (2010), such as eliminating or reducing a disturbance factor or its impact.

The aim of the control list presented in this section is to support the developer in the systematic identification of disturbance factors already on the conceptual level by providing a list that ensures that potentially relevant disturbance factors are considered with regard to their occurrence. Therefore, the presented control list builds up on the basic concept of the control list by Vorwerk-Handing et al. (2020) and the fundamentals of multipole based model theory, described in section 2.4. In order to ensure the systematics and applicability of the developed control list, special attention was payed to the problems of the control list by Vorwerk-Handing et al. (2020) that were addressed in section 2.5. In the following, the basic structure and concept of the developed control list is generally described. In this context, the approach for the development of the control list is also outlined. Subsequently, an extract from the developed control list is shown and explained in more detail.

\subsection{Basic structure and concept of the developed control list}

The developed control list is structured based on physical domains and, if applicable, subdomains of the included disturbance factors. Physical domains are, for example, mechanics, electricity and magnetism as well as thermodynamics (cf. Janschek, 2010). Each disturbance factor related to a (sub-) domain is listed as individual line entry in combination with its respective pictogram, a processing field for its occurrence as well as its physical influencing variables and a field for the quantification of the disturbance factor respectively its physical influencing variables. The characteristic pictograms enable an easy and efficient identification of the listed disturbance factors. The general structure of the developed control list builds up on the basic structure of the control list by Vorwerk-Handing et al. (2020) and is illustrated in Figure 6. 
In the course of the identification and definition of disturbance factors to be included in the control list, the list of standardised disturbance factors from Mathias (2016) was first analysed in detail for existing ambiguities as well as inconsistencies in its level of detail. Based on this information, the list of standardised disturbance factors was first reduced by summarizing similar disturbance factors, for example heat supply and heat dissipation, as well as extended in some points, for example in the field of nuclear physics, to achieve a uniform level of detail and eliminate ambiguities. In the next step, the modified list was structured according to the addressed physical (sub-) domain of each disturbance factor, similar to the control list from Vorwerk-Handing et al. (2020). Subsequently, each disturbance factor was analysed with the help of guide words, like the ones used in HAZOP to predict malfunctions or deviations, for example, "more/less", "invert" or "otherwise" to systematically generate disturbance factors that were not yet included and thus unconsidered. In order to be able to control the amount of disturbance factors generated with this divergent approach, the additionally identified disturbance factors were analysed and compared with the already included disturbance factors regarding their similarity and if possible combined. Using this convergent approach, on the one hand, the total number of disturbance factors included in the control list was reduced and, on the other hand, ambiguities regarding the exact differentiation of similar disturbance variables were avoided. It must be noted at this point, that in a few cases a disturbance factor is relevant in more than one physical domain and thus is included more than once in the control list. An example for such a disturbance factor is $\gamma$-radiation which is included in the physical domain "nuclear physics" as well as in the domain "electricity and magnetism" in the subdomain "electromagnetic radiation".

Each identified disturbance factor is generally characterised by its physical influencing variables that directly act on the considered system and may cause unintended physical effects (cf. VorwerkHanding et al., 2020). As described in section 2.4, the energy transfer between two network elements, in this context between the considered technical system and its environment, is describable using a generalised flow variable $f$ and a generalised effort variable $e$. Thus, these two variables are sufficient to fully describe a disturbance factor. The same applies to the energy transfer from the technical system to its environment in terms of secondary variables. The interactions between a technical system and its environment are shown in Figure 5.

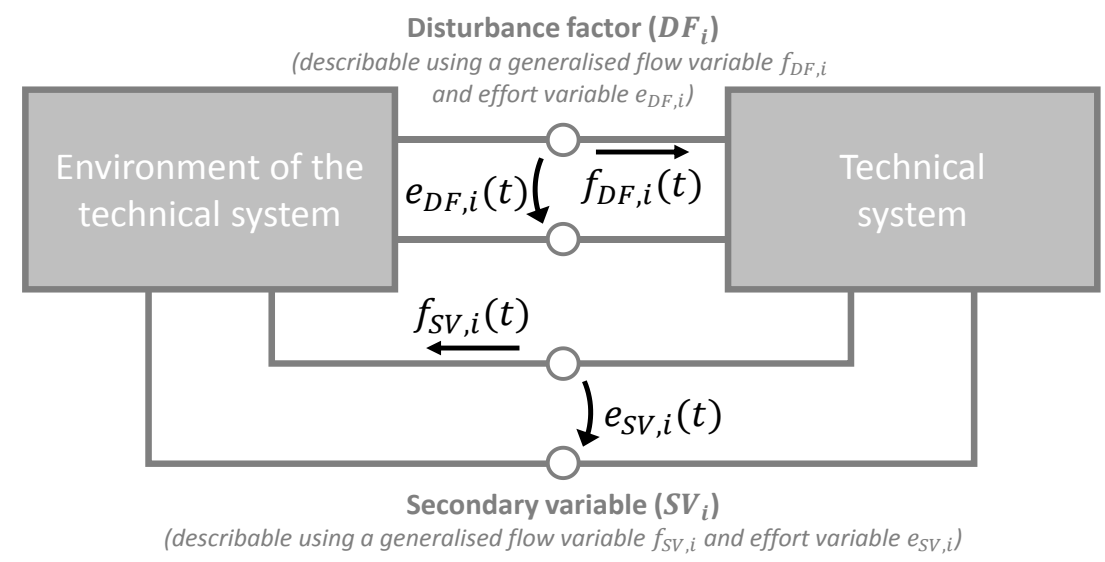

Figure 5: Interactions between a technical system and its environment (based on Wellstead, 1979)

The physical effects caused by the physical influencing variables of occurring disturbance factors can be systematically identified using the effect catalogue of Vorwerk-Handing (2021). This catalogue system is also based on the principles of multipole based model theory and thus includes the generalised flow and effort variables of the different physical domains as input and output of known physical effects. The generalised energy variables of each occurring disturbance factor are considered as input of unintended physical effects, which can negatively influence the functionality of the technical system. An example for such a negative influence is the dependence of a functionally relevant input quantity on an acting physical influencing variables, which results in an impermissible deviation of this quantity.

The last column in the control list is used for the quantification of the corresponding physical influencing variables of the occurring disturbance factors. By quantifying these variables, the developer determines the present level of uncertainty, as described in section 2.3, associated with the individual disturbance factors. Therefore, the developer must check the availability and reliability of 
information regarding the concerned disturbance factor that are needed for its quantification. If the developer is not able to quantify the physical influencing variables, there is a lack of information, which indicates that measures to control uncertainty may be necessary. In this context, the nature of uncertainty, as described in section 2.3, must also be taken into account to ensure the effectiveness of information-generating measures, such as experimental studies.

\subsection{Extract of the developed control list}

The presented control list supports the developer in the systematic identification of disturbance factors already in the early phase of concept development. In addition, by connecting the disturbance factors with their physical influencing variables based on multipole based model theory, it provides a basis for the subsequent identification of unintended physical effects caused by them using the effect catalogue of Vorwerk-Handing (2021). Since the basic structure and concept of the developed control list were generally described in the previous section, an extract of the developed control list for the physical domains mechanics, electricity and magnetism as well as thermodynamics is shown in Figure 6.

\begin{tabular}{|c|c|c|c|c|c|c|}
\hline & & Disturbance factor & Pictogram & Occurrence & $\begin{array}{l}\text { Physical influencing } \\
\text { variables* }\end{array}$ & Quantification \\
\hline \multirow{3}{*}{ 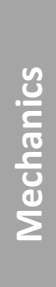 } & \multirow{2}{*}{ 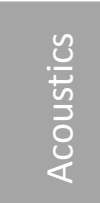 } & $\begin{array}{l}\text { Structure-borne } \\
\text { sound }\end{array}$ & \rangle & $\square$ & $\begin{array}{l}\text { Force }(F) \\
\text { Velocity }(v)\end{array}$ & \\
\hline & & $\begin{array}{l}\text { Fluid-borne } \\
\text { sound }\end{array}$ & & $\square$ & $\begin{array}{l}\text { Volume flow }(\dot{V}) \\
\text { Pressure }(p)\end{array}$ & \\
\hline & $\vdots$ & $\ldots$ & $\ldots$ & $\ldots$ & $\ldots$ & $\ldots$ \\
\hline \multirow{6}{*}{ 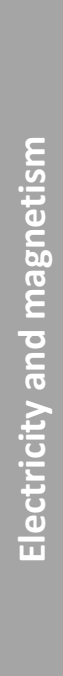 } & \multirow{3}{*}{ 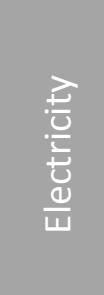 } & $\begin{array}{c}\text { Change in electric } \\
\text { voltage }\end{array}$ & 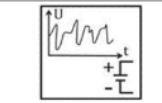 & $\square$ & $\begin{array}{l}\text { Electric current }(I) \\
\text { Electric voltage }(U)\end{array}$ & \\
\hline & & Electric field (static) & 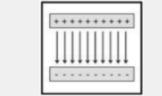 & $\square$ & $\begin{array}{l}\text { Electric current }(I) \\
\text { Electric voltage }(U)\end{array}$ & \\
\hline & & $\ldots$ & $\ldots$ & $\cdots$ & $\ldots$ & $\ldots$ \\
\hline & \multirow{2}{*}{ 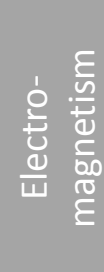 } & $\begin{array}{l}\text { Electromagnetic } \\
\text { field (static) }\end{array}$ & $\Rightarrow$ & $\square$ & $\begin{array}{l}\text { Magnetic flux }\left(\Phi_{m}\right) \\
\text { Magnetomotive } \\
\text { force }\left(V_{m}\right)\end{array}$ & \\
\hline & & $\begin{array}{l}\text { Electromagnetic } \\
\text { radiation }\end{array}$ & $(((c)))$ & $\square$ & $\begin{array}{l}\text { Magnetic flux }\left(\Phi_{m}\right) \\
\text { Magnetomotive } \\
\text { force }\left(V_{m}\right)\end{array}$ & \\
\hline & $\vdots$ & $\ldots$ & $\ldots$ & $\ldots$ & $\ldots$ & $\ldots$ \\
\hline \multirow{4}{*}{ 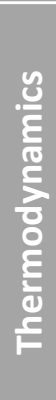 } & \multirow{3}{*}{ 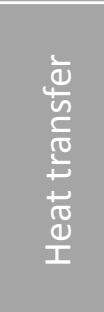 } & Heat conduction & 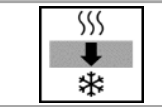 & $\square$ & $\begin{array}{l}\text { Entropy flow }(\dot{S}) \\
\text { Temperature }(T)\end{array}$ & \\
\hline & & Heat convection & 峛 & $\square$ & $\begin{array}{l}\text { Entropy flow }(\dot{S}) \\
\text { Temperature }(T)\end{array}$ & \\
\hline & & Heat radiation & $\stackrel{\text { S⿰S }}{=}$ & $\square$ & $\begin{array}{l}\text { Entropy flow }(\dot{S}) \\
\text { Temperature }(T)\end{array}$ & \\
\hline & $\vdots$ & $\ldots$ & $\ldots$ & $\ldots$ & $\ldots$ & $\ldots$ \\
\hline
\end{tabular}

Figure 6: Extract of the developed control list (pictograms based on Mathias, 2016) 


\section{CONCLUSION AND OUTLOOK}

The control list presented in this contribution builds up on the basic concept and structure of the control list by Vorwerk-Handing et al. (2020) and the fundamentals of multipole based model theory in order to support the developer in the systematic identification of disturbance factors that may affect the considered systems functionality or stability on the conceptual level.

The presented control list is structured based on physical domains which allows the developer to decide whether the majority of disturbance factors is considered or some (sub-) disciplines are neglected. A reasonable decision for neglecting (sub-) disciplines may be, for example, that the developer has sufficient knowledge and/or experience to rule out its relevancy regarding the criticality of the therein included disturbance factors for the functionality as well as safety of the considered system. This can be critical both with regard to unexperienced developers and to time-critical development processes if some (sub-) disciplines are mistakenly neglected even though they have a major impact on the functionality of the considered system. A solution for this problem is yet to be identified.

The disturbance factors included in the presented control list are based on the list of standardised disturbance factors by Mathias (2016). The original list was first revised to achieve a uniform level of detail and eliminate ambiguities. After that, the remaining disturbance factors were analysed using the help of guide words to identify not yet considered disturbance factors and ensure that the majority of potential disturbance factors is included in the control list. At this point it must be mentioned, that the completeness of the developed control list can never be guaranteed due to the permanent technological progress which may result in new, and thus yet unknown, disturbance factors. To counteract this problem, it is required to regularly update the control list. Furthermore, the pictograms of some disturbance factors still need to be designed and added to the control list.

In order to characterise the different disturbance factors included in the control list, physical influencing variables were assigned to each disturbance factor that directly act on the considered system. In this case, the physical influencing variables of a disturbance factor are the two (sub-) domain specific generalised energy variables, which were derived using the approach of multipole based model theory. These variables can be used in a later step to systematically identify caused unintended physical effects with the effect catalogue proposed by Vorwerk-Handing (2021).

In a next step, an extension of the developed control list regarding an additional column for the documentation of the different sources of the individual disturbance factors is conceivable. This information may be useful for the developer in terms of the development of suitable robust design measures to increase the robustness of the considered system if required.

After that, an initial evaluation of the developed control list is planned in the framework of the development of an innovative product in order to assess the applicability as well as the usability of the control list for product developers. In this context, the usage of the control list by inexperienced developers is also intended in order to be able to assess its comprehensibility and intuitiveness.

As described in section 2.1, Taguchi et al. (2005) define another type of noise, named noise due to internal causes, that originates from within the technical system due to some kind of internal variation, for example, of material or geometric properties. Similar to disturbance factors, it also results in a deviation of the systems behaviour from expectation and thus is of importance for the developer. For this reason, it is planned to include this type of noise in the control list in the future. However, since this type of noise does not cause an energy transfer, but affect the law of the energy flow within the system, it cannot be identified with the presented control list. Consequently, a different approach needs to be developed to consider this type of noise. By including noise due to internal causes, it would be possible, among other things, to include disturbance factors from the domain "physical chemistry", such as the chemical introduced change of a process medium or material properties.

\section{ACKNOWLEDGMENTS}

The authors would like to thank the Deutsche Forschungsgemeinschaft (DFG, German Research Foundation), which funded the presented research in the framework of the project "Derivation of analysis- and synthesis-methods to manage uncertainty in the development of mechatronic systems with sensor integrating machine elements".

Gefördert durch die Deutsch Forschungsgemeinschaft (DFG) - 426030644

Funded by the Deutsche Forschungsgemeinschaft (DFG, German Research Foundation) - 426030644 


\section{REFERENCES}

Andersson, P. (1997), “On Robust Design in the Conceptual Design Phase: A Qualitative Approach”, Journal of Engineering Design, Vol. 8 No. 1, pp. 75-89.

Chakhunashvili, A., Johansson, P.M. and Bergman, B.L.S. (2004), "Variation mode and effect analysis", in Annual Symposium Reliability and Maintainability, 2004 - RAMS, Jan. 26-29, 2004, Los Angeles, CA, USA, IEEE, pp. 364-369.

Engelhardt, R., Koenen, J.F., Enss, G.C., Sichau, A., Platz, R., Kloberdanz, H., Birkhofer, H. and Hanselka, H. (2010), "A Model to Categorise Uncertainty in Load-Carrying Systems", 1st MMEP International Conference on Modelling and Management Engineering Processes, pp. 53-64.

Feldhusen, J. and Grote, K.-H. (Eds.) (2013), Pahl/Beitz Konstruktionslehre: Methoden und Anwendung erfolgreicher Produktentwicklung, 8th ed., Springer Berlin Heidelberg; Springer International Publishing AG, Berlin, Heidelberg, Cham.

Galbraith, J.R. (1973), Designing complex organizations, Organization development, Addison-Wesley, Reading, Mass.

Hanselka, H. and Platz, R. (2010), “Ansätze und Maßnahmen zur Beherrschung von Unsicherheit in lasttragenden Systemen des Maschinenbaus", Konstruktion, 11/12, pp. 55-62.

Heinrich, B. and Schneider, W. (2019), Grundlagen Regelungstechnik: Einfache Übungen, praktische Beispiele und komplexe Aufgaben, Lehrbuch, 5th revised and extended ed., Springer Vieweg, Wiesbaden.

International Organization for Standardization (2009), Risk management: Vocabulary (ISO Guide 73), November 2009, Beuth, Berlin.

Janschek, K. (2010), Systementwurf mechatronischer Systeme: Methoden - Modelle - Konzepte, Springer, Berlin.

Koller, R. (1998), Konstruktionslehre für den Maschinenbau: Grundlagen zur Neu- und Weiterentwicklung technischer Produkte mit Beispielen; mit 16 Tabellen, 4th revised and extended ed., Springer, Berlin.

Kreye, M.E., Goh, Y. and Newnes, L.B. (2011), "Manifestation of uncertainty. a classification", in Proceedings of the 18th International Conference on Engineering Design, ICED 11, Design Society, København, pp. 96-107.

Lotz, J. (2018), "Beherrschung von Unsicherheit in der Baureihenentwicklung”, Dissertation, Technical University of Darmstadt, Darmstadt, 2018.

Mathias, J. (2016), “Auf dem Weg zu robusten Lösungen”, Doctoral Thesis, Technical University of Darmstadt, Darmstadt, 2016.

Mathias, J., Kloberdanz, H., Engelhardt, R. and Birkhofer, H. (2010), "Strategies and principles to design robust products", DS 60: Proceedings of DESIGN 2010, the 11th International Design Conference, Dubrovnik, Croatia, pp. 341-350.

Oberkampf, W.L., DeLand, S.M., Rutherford, B.M., Diegert, K.V. and Alvin, K.F. (2002), "Error and uncertainty in modeling and simulation", Reliability Engineering \& System Safety, Vol. 75 No. 3, pp. 333-357.

Pahl, G., Beitz, W., Feldhusen, J. and Grote, K.-H. (2007), Engineering Design: A Systematic Approach, 3rd ed., Springer London; Springer International Publishing AG, London, Cham.

Taguchi, G., Chowdhury, S., Wu, Y., Taguchi, S. and Yano, H. (Eds.) (2005), Taguchi's quality engineering handbook, John Wiley \& Sons, Hoboken, N.J.

Vorwerk-Handing, G. (2021), "Erfassung systemspezifischer Zustandsgrößen. Physikalische Effektkataloge zur systematischen Identifikation potentieller Messgrößen”, Doctoral Thesis, Technical University of Darmstadt, Darmstadt, 2021.

Vorwerk-Handing, G., Martin, G. and Kirchner, E. (2018), "Integration of Measurement Functions in Existing Systems - Retrofitting as Basis for Digitalization", paper presented at NordDesign 2018.

Vorwerk-Handing, G., Welzbacher, P. and Kirchner, E. (2020), "Consideration of uncertainty within the conceptual integration of measurement functions into existing systems", Procedia Manufacturing, Vol. 52, pp. 301-306.

Walker, W.E., Harremoës, P., Rotmans, J., van der Sluijs, J.P., van Asselt, M.B.A., Janssen, P. and Krayer von Krauss, M.P. (2003), "Defining Uncertainty: A Conceptual Basis for Uncertainty Management in ModelBased Decision Support", Integrated Assessment, Vol. 4 No. 1, pp. 5-17.

Wellstead, P.E. (1979), Introduction to physical system modelling, Acad. Pr, London [etc.]. 